\title{
LETTER FROM THE EXECUTIVE DIRECTOR
}

I am delighted to announce the results of the 2009 elections: the Vice President elect is Judith Byfield (History, Cornell U). The Board members elect are Teresa Barnes History, U of Illinois Urbana-Champaign, Catherine Boone (Political Science/Government, U of Texas at Austin), and Richard Schroeder (Geography, Rutgers U). The Board extends its sincerest appreciation to the ASA members who cast their votes and to all the candidates for their willingness to serve the Association. The new election calendar concludes in the spring rather than in the fall and will assist the Nominating Committee in achieving ever greater diversity in identifying individuals whose commitment, energy, and ideas will shape the Association's strategy and future.

The ASA community, from the academy, from government, and from non-governmental organizations, is the raison d'être for the Association's mission of bringing together people with a scholarly and professional interest in Africa. This vibrant community of Africanists convenes via the website, via the Association's journals, and via the Annual Meeting - dynamic venues that serve as clearinghouses for expertise about Africa: online, in print, and in person.

I hope you will continue to explore the website's many new features and become increasingly comfortable with using it as a tool to engage with the Association and the Africanist community year-round, i.e., to network using the ASA Directory, which is available to members only, and to collaborate in the available myASA fora. In addition to virtual interaction, contribute to evolving discussions in the African Studies Review, which is a member benefit, and in the subscription journal, History in Africa. I nteract with colleagues in person by participating in the Annual Meeting, at a discounted rate for ASA members. At the Annual Meeting, you will learn about ASA highlights during the Business Meeting, celebrate excellence in the field during the Presidential Lecture and Awards Ceremony, and bring your comments, compliments, and concerns to the ASA Town Hall. Avail yourself of these opportunities within the Association to strengthen your individual professional endeavors, while simultaneously advancing the ASA's goal of promoting African studies.

The ASA's fiftieth anniversary celebrations, focusing first on "21st Century Africa: Evolving Conceptions of Human Rights" in New York, NY in 2007, then on "Knowledge of Africa: The Next Fifty Years," in Chicago, IL, in 2008, helped to lay a solid scholarly and professional foundation for "Africa at a Crossroads," the theme of this year's Annual Meeting, which will be held November 19-22 in New Orleans, LA. The preliminary program will be available on the ASA website in July; visit www. africanstudies.org for updated travel, hotel, and other information.

The ASA recently has added new member benefits and services that are specifically aimed at helping you to engage in research, teaching, and professional work more effectively. ASA members who wish to duplicate and distribute articles published in any ASA journal for their own courses may do so without seeking permission from the ASA; please remember to cite the details of publication in the specific journal by author, title, volume, number, date, and inclusive pagination. Coordinate organizations now have a clear link on the ASA's home page and may use the community function to reach all their members with announcements, news, and other correspondence. Coordinate Organization officers are invited to meet with Board members during the Annual Meeting to share ideas and to discuss future collaboration. We're excited to provide these new benefits to ASA members.

Mutual support is especially important in times of economic challenge - for individuals and for the ASA community to which we belong. The ASA budget relies almost entirely on revenue from membership dues, Annual Meeting registration and exhibit booth fees, advertising, and the sale of ASA publications. The Board passed a balanced budget for 2009 and we are aggressively monitoring expenses. But we need revenue to ensure that the Association emerges whole, despite the difficult economy. We need to pursue an active campaign of "Each One Reach One." Renew your own membership if you have not already done so, then immediately contact at least one colleague, center, institute, or organization and urge them to become an individual member or an institutional subscriber. Urge them to attend the Annual Meeting. Urge them to participate in the ASA Exhibit Hall, with a commercial or charitable booth(s), or as part of the Combined Book Exhibit at the ASA booth. Urge them to place an ad in an ASA publication or to purchase the ASA mailing list to announce new books, films, openings, and other events. And, "Give or Get" support for the ASA endowment, secure in the knowledge that every contribution is important and every donation counts. Now, more than ever, let us work together to sustain the Association's operations and programs. Thank you! 